\title{
Modeling of intangible assets development and improvement processes in the enterprise management
}

\author{
M.P. Voynarenko ${ }^{1}$, V.M. Dzhuliy ${ }^{2}$, L.V.Dzhuliy ${ }^{\text {a }}$, L.V. Yemchuk ${ }^{4}$ \\ 1 . 4 Department of Accounting, Audit and Taxation, Khmelnytskiy National University \\ ${ }^{a}$ Department of Cybersecurity, Computer Systems and Networks, Khmelnytskiy National University
}

\section{Article Info}

Received Feb 5, 2019

\section{Keyword:}

Assets

Development

Economic and mathematical

modeling

Intangible management

Optimal plan

Planning

\begin{abstract}
The economic fundamentals of intangible assets topicality, their development in the context of targeted operational and strategic planning of enterprises' activities are described. The scientific and methodical approach was proposed to constructing a linear function of the enterprise's intangible assets improvement and development plan, to estimating of the linear function plan adequacy to the input data, to determining of the optimal plan for a given set of factor characteristics, and to determining of the plan indicators' reference values. The method of assessing the effectiveness of the enterprise's intangible assets improvement and development plan is elaborated, which provides an opportunity to take into account all changes taking place in its informational-economic, intellectual, financial and organizational spheres.
\end{abstract}

\section{Corresponding Author:}

L.V. Yemchuk

Department of Accounting, Audit and Taxation,

Khmelnytskiy National University,

Apt.12, proyizd P. Myrnoho, 3/12, city Khmelnitsky, Khmelnitsky region, 29027, Ukraine

Email: yemchuk777@gmail.com

\section{Introduction}

The rapid development of scientific and technological progress, raising the level of production processes informatization and intellectualization, and intensification of production and intellectual capital non-material factors use are generally accepted trends in the transition to the post-industrial stage of civilization development [9], [10]. Therefore, the activities associated with the intangible assets formation and use greatly affects the achievement of the company's success in the competitive struggle inherent in a market economy [14], [15]. This entails the need for a sound approach to managing the processes of enterprise intangible assets formation, since their state of use, as well as the further improvement and development areas, and the risks associated with them, do not always have quantitative dimensions, but require qualitative assessments, with appropriate application of economic and mathematical methods and models. In this regard, the company's management system faces the challenge of a sound choice of options for the intangible assets development (by their types), with elements of quantitative and qualitative indicators planning and a comprehensive solution of production and economic tasks.

The conducted research allows stating an important fact fixed by the scientists that only one from each 6 
dollars of enterprise investments market value is fixed in balance of the companies, while the last five dollars represent intangible assets [7]. We agree with the opinion of scientists that information and intellectual capital is the basis of intangible assets, improving the quality of enterprise management and its activities effectiveness [11]. At the same time, the results of many scientific studies show that the competitive and economic benefits that a firm derives from the use of various types of intangible assets related to the development of informational systems are in firm's ability to apply them in management [12], [6]. Consequently, the intangible assets investment provides a qualitatively new level of enterprise's management activity and increases profitability. However, it should be borne in mind that the intangible assets development requires significant investments and is inherently innovative, therefore it is important to take into account the management process risks [1] related to the intangible assets formation, as well as both operational and strategic development and improvement planning optimization.

There are traditional approaches in economic science and practical activity as to using optimization methods for modelling many economic processes [17]. V. Andriienko, I. Ivchenko, Z. Sokolovska, A. Yepifanov and many other scientists consider the problems of econometric and mathematical modelling wide use in the study of complex economic systems and processes associated with real (tangible) assets [8], [19]. Researches in the field of intangible assets are focused on their assessment according to the reporting companies [20], or from the point of view of their impact on the value capitalization [18], economic security [13], etc. It is reasonable to expand scientific and methodological approaches in the construction of an integrated approach in solving problems of enterprises' intangible assets planning and development, thus giving the possibility of assessing the intangible assets role in enterprises' strategic objectives implementation, and their sustainable economic growth.

\section{The unsoved part of the problem}

Intangible assets are a complex economic category consisting of many economic elements [5]. The absence of such components material form (software, databases, intellectual and informational components, etc.) explains the situation that such assets are difficult to quantify [2] (only a natural-cost estimate of individual components on the date of their acquisition or creation and at the stages of use is possible [13]). Then for the intangible assets formation management, their further improvement and rapid development, it is necessary to develop new tools of a separate variants reasonable choice basing first and foremost on qualitative as well as on quantitative indicators. It is expedient to define such indicators in the context of enterprise operation target direction, its organizational and economic changes. For this purpose it is advisable to carry out expert assessments using the tools of economic-mathematical modeling [3], [7]. We share the opinion of Y. Samokhvalov and Y. Naumenko, that the expert method in combination with other economic and mathematical methods can serve as a constructive tool for the study of complex economic systems which include the processes of using intangible assets at enterprises [16]. Highly qualified specialists from many fields of knowledge and practical experience who can make a qualitative assessment of the actual changes taking place with the enterprises intangible assets use and identify available forecasting directions should join to the experts. This will allow assessing the effectiveness of alternative planning options [21], optimizing measures for the enterprises' intangible assets formation to ensure the efficiency of their functioning in the long run.

\section{Materials and methods}

When considering the question of substantiation of the intangible assets formation processes and the appropriate measures implementation, it is expedient to develop a reference plan of the effectiveness assessment (feasibility) of measures.

Such a sequence involves solving interdependent tasks: developing a reference plan mathematical model and calculating the factor characteristics numerical values (variables of this plan); elaborating of the plan effectiveness mathematical model and the methodology of alternative plans effectiveness assessing as compared to that of the reference plan. Thus, the calculation of the reference plan of intangible assets development is an important part of the enterprises strategic development planning, and the mathematical 
interpretation of the intangible assets development planning is carried out in the following sequence.

\section{Planning processes modeling of the intangible assets development and improvement}

Let's take an $m \times n$-sized matrix of the measures plan derived from the experts questionnaire data, where $\mathrm{m}-$ is the number of experts (the number of the matrix rows), and $n$ is the number of factor characteristics (number of columns), $m \geq n ; \quad x_{i j}$ i is the matrix element in absolute units (the real value of the $\mathrm{J}$ factor, estimated by the $\mathrm{i}$-th expert)., $i=1,2, \ldots, m ; j=1,2, \ldots, n$. It is necessary to find the following linear function of a plan that will most closely match the original expert estimates:

$$
Z=a_{1} x_{1}+a_{2} x_{2}+a_{3} x_{3}+\ldots+a_{n} x_{n}=\sum_{j=1}^{n} a_{j} x_{j},
$$

As it is known, the equation 1 determines also some hyperplane in space $R^{n}$. With an ideal coincidence of numerical values of factor marks expert estimates, the reference plan would be depicted on a plane (1) with a single point with a hyperplantation:

$$
Z=k\left(x_{1}^{*}, x_{2}^{*}, x_{3}^{*}, \ldots, x_{n}^{*}\right),
$$

However, the opinions of the experts do not coincide, and therefore each line of the matrix on the plane (1) will correspond to some point with the applicator

$$
Z_{i}=a_{1} x_{i 1}+a_{2} x_{i 2}+a_{3} x_{i 3}+\ldots+a_{n} x_{i n},
$$

that is, the set of points that do not coincide with the reference plan point i scattered randomly near it. Suppose that the expert survey obligatory condition of the expressed estimates equivalence is fulfilled. Then we can assume that all the points $z_{i}$ belong to one hyperplane of the desired reference plan, and the deviations $k-Z_{i}$ are random. To calculate the coefficients $a_{j}$ of the linear model (1) we apply the method of least squares, which minimizes the sum of squares of points $Z_{i}$ deviations from the point $k$. The agreement criterion of the desired function (1) we will take such a set of $\left\{a_{1}, a_{2}, a_{3}, \ldots, a_{n}\right\}$, coefficients which satisfies the least squares method

$$
S=\frac{1}{m} \cdot \sum_{i=1}^{m}\left(k-z_{i}\right)^{2}=\frac{1}{m} \sum_{i=1}^{m}\left(k-\sum_{j=1}^{n} a_{j} x_{i j}\right)^{2} \longrightarrow \min
$$

where $k$ - is the plan function value at the optimum point $\left(x_{1}^{*}, x_{2}^{*}, x_{3}^{*} \ldots, x_{n}^{*}\right), x_{j}^{*}$ - reference values of the factors $\mathrm{X}_{\mathrm{j}}, Z_{i}$ - and is the system function value at the point $\left(x_{i 1}, x_{i 2}, x_{i 3} \ldots, x_{i n}\right)$.

Taking into account the condition (4) for calculating the coefficients of a plan linear model leads to a system of so-called $\mathrm{m}$ conditional equations with $\mathrm{n}$ unknowns, which then transforms into a system $\mathrm{n}$ normal equations with unknowns $a_{j}$. The constructed system will have the form:

$$
\left\{\begin{array}{l}
a_{1} \sum x_{i 1}^{2}+a_{2} \sum x_{i 1} x_{i 2}+a_{3} \sum x_{i 1} x_{i 3} \ldots+a_{n} \sum x_{i 1} x_{i n}=k \sum x_{i 1} \\
a_{1} \sum x_{i 1} x_{i 2}+a_{2} \sum x_{i 2}^{2}+a_{3} \sum x_{i 2} x_{i 3} \ldots+a_{n} \sum x_{i 2} x_{i n}=k \sum x_{i 2} \\
a_{1} \sum x_{i 1} x_{i 3}+a_{2} \sum x_{i 2} x_{i 3}+a_{3} \sum x_{i 3}^{2} \ldots+a_{n} \sum x_{i 3} x_{i n}=k \sum x_{i 3} \\
\hdashline \ldots \ldots \ldots \ldots \ldots \ldots \ldots \ldots \\
a_{1} \sum x_{i 1} x_{i n}+a_{2} \sum x_{i 2} x_{i n}+a_{3} \sum x_{i 3} x_{i n} \ldots+a_{n} \sum x_{i n}^{2}=k \sum x_{i n}
\end{array}\right.
$$

where the summation is performed on i from 1 to $\mathrm{m}$. By the Cramer's rule, we find its solution to the arbitrary multiplier $\mathrm{k} \neq 0$. The solution of system (5) is expressed by equations:

$$
a_{1}=\frac{k \Delta_{1}}{\Delta}, a_{2}=\frac{k \Delta_{2}}{\Delta}, a_{3}=\frac{k \Delta_{3}}{\Delta}, \ldots, a_{n}=\frac{k \Delta_{n}}{\Delta},
$$

where $\Delta-$ is the main determinant of the system (5); 


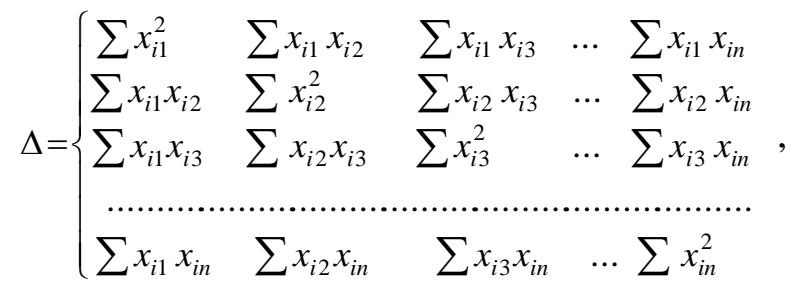

$k \Delta_{j}$ - determinants that are formed with $\Delta$ replacement of the $j$-th column by the free members column (5). Taking into account (6) the plan output function is as follows:

$$
Z=k\left(\frac{\Delta_{1}}{\Delta} x_{1}+\frac{\Delta_{2}}{\Delta} x_{2}+\frac{\Delta_{3}}{\Delta} x_{3}+\ldots+\frac{\Delta_{n}}{\Delta} x_{n}\right),
$$

where $\mathrm{k} \neq 0$ - is an arbitrary given parameter.

Function (8) defines a one-parameter family of hyperplanes formed with the accuracy of "parallel" transfer $\mathrm{k} \neq 0$ along the coordinate $\mathrm{Oz}$ of $\mathrm{n}$-dimensional space. By fixing $\mathrm{k}$, we get one of them. Note that the arbitrary choice of $\mathrm{k}$, although it changes the coefficients (6) of the linear model (8), but these coefficients for each $\mathrm{k}$ satisfy the condition (4), since in the case of parallel transfer of the hyperplane deviations $k-Z_{i}$ remain unchanged.

In other words, for any $\mathrm{k}$ the coefficients (6) will perfectly correspond to the expert estimates. Let's add equality (2) to equation (8), and we obtain:

$$
\left\{\begin{array}{l}
Z=k \\
Z=k
\end{array}\left(\frac{\Delta_{1}}{\Delta} x_{1}+\frac{\Delta_{2}}{\Delta} x_{2}+\frac{\Delta_{3}}{\Delta} x_{3}+\ldots+\frac{\Delta_{n}}{\Delta} x_{n}\right),\right.
$$

The hyperline of operational plans is determined by these equations in space $R^{n}$. It follows from (9) that every plan whose variables satisfy identity:

$$
1=k\left(\frac{\Delta_{1}}{\Delta} x_{1}+\frac{\Delta_{2}}{\Delta} x_{2}+\frac{\Delta_{3}}{\Delta} x_{3}+\ldots+\frac{\Delta_{n}}{\Delta} x_{n}\right)
$$

is considered operational. Condition (10) is a prerequisite for the proposed plan to be operational. For all further cases we will assume $\mathrm{k}=1$ and the function of the plan (operational plans hyperline) will be determined by the system of equations:

$$
\left\{\begin{array}{l}
Z=k\left(\frac{\Delta_{1}}{\Delta} x_{1}+\frac{\Delta_{2}}{\Delta} x_{2}+\frac{\Delta_{3}}{\Delta} x_{3}+\ldots+\frac{\Delta_{n}}{\Delta} x_{n}\right), \\
Z=1
\end{array}\right.
$$

The mathematical model adequacy assessment of the plan by the resulting data

Let's evaluate the mathematical model adequacy to the resulting data. The plan function should be examined for the input data adequacy (Table 1) by the Fisher criterion, based on the inequality

$$
F<F_{T}\left(\alpha, k_{1}, k_{2}\right),
$$

where is the calculated criterion value; $F_{T}$ is the theoretical criterion value; $\alpha$ is a five-percent significance level; $k_{1}=m-n, k_{2}=m-1$ is the number of degrees of freedom. The estimated value of $F$ is determined by the formulas: 


$$
\left\{\begin{array}{c}
F=\frac{D_{A}}{D_{B}} \\
D_{A}=\frac{1}{m-n} \sum_{i=1}^{m}\left(Z_{i}-k\right)^{2} \\
D_{B}=\frac{1}{m-n} \sum_{i=1}^{m}\left(Z_{i}-\bar{Z}\right)^{2}
\end{array}\right.
$$

where $D_{A}$ is the variance of adequacy, $D_{B}$ is the variance of reproduction. We accept $k=1 ; Z_{i}$ is the estimated function value of the plan in the line $i$ on expert estimates $x_{i j} ; \bar{Z}-$ is average with $Z_{i}$. If inequality (12) is not fulfilled, then we have to pick up an algebraic function of higher order instead of the linear model (1). Let's note that the construction of a nonlinear algebraic plan function is a labor-intensive task, therefore it is expedient to use software for its solution.

\section{Method for the operational plans and the multi-criteria optimal (reference) plan determining}

We will call any plan that corresponds to the factor characteristics given value obtained by expert estimates an admissible plan for the intangible assets development and improvement. In accordance with this definition, the necessary and sufficient condition for the proposed plan admissibility $\left\{x_{1}, x_{2}, x_{3}, \ldots, x_{n}\right\}$ on the accepted set of factor characteristics is the implementation of the inequalities:

$$
\left\{\begin{array}{l}
\min \left\{x_{i 1}\right\} \leq x_{1} \leq \max \left\{x_{i 1}\right\} \\
\min \left\{x_{i 2}\right\} \leq x_{2} \leq \max \left\{x_{i 2}\right\} \\
\min \left\{x_{i 3}\right\} \leq x_{3} \leq \max \left\{x_{i 3}\right\} \\
\cdots \cdots \cdots \cdots \cdots \cdots \cdots \cdots \cdots \cdots \cdots \\
\min \left\{x_{i n}\right\} \leq x_{n} \leq \max \left\{x_{i n}\right\}
\end{array}\right.
$$

There is an innumerable set of plans that satisfy inequalities $(*)$. In this set we call plans operational if their variables identically satisfy the hyperline equation (11), so that:

$$
\frac{\Delta_{1}}{\Delta} x_{1}+\frac{\Delta_{2}}{\Delta} x_{2}+\frac{\Delta_{3}}{\Delta} x_{3}+\ldots+\frac{\Delta_{n}}{\Delta} x_{n} \equiv 1,
$$

To determine the operational plans, you must do the following. To determine the operational plans, you must do the following. Let us denote any points of $Z_{r}, Z_{s}$ expert estimates by $E_{r}, E_{s}$ on the hyperplane of the planes on both sides of the hyperline (11), so that

$$
\left\{\begin{array}{c}
1-Z_{r}>0 \\
1-Z_{s}<0, r, s \in i
\end{array}\right.
$$

Fig. 1 shows two sets of such points for the Euclidean space $R^{3}$. Then it is obvious that the operational plans will be represented by the countable set of points $A\left(x_{1}, x_{2}, x_{3}, \ldots, x_{n}\right)_{A}, B\left(x_{1}, x_{2}, x_{3}, \ldots, x_{n}\right)_{B}$, $G\left(x_{1}, x_{2}, x_{3}, \ldots, x_{n}\right)_{G}$ and intersections of hyper lines $E_{r}, E_{s}$ with the hyperline LM plans. In fig. 1 there are six of such points. To find the coordinates of the points $A, B, \ldots, G$, that is the set of operational plans $\left(x_{1}, x_{2}, x_{3}, \ldots, x_{n}\right)_{A},\left(x_{1}, x_{2}, x_{3}, \ldots, x_{n}\right)_{B},\left(x_{1}, x_{2}, x_{3}, \ldots, x_{n}\right)_{G}$, it is necessary to do the following operations: 


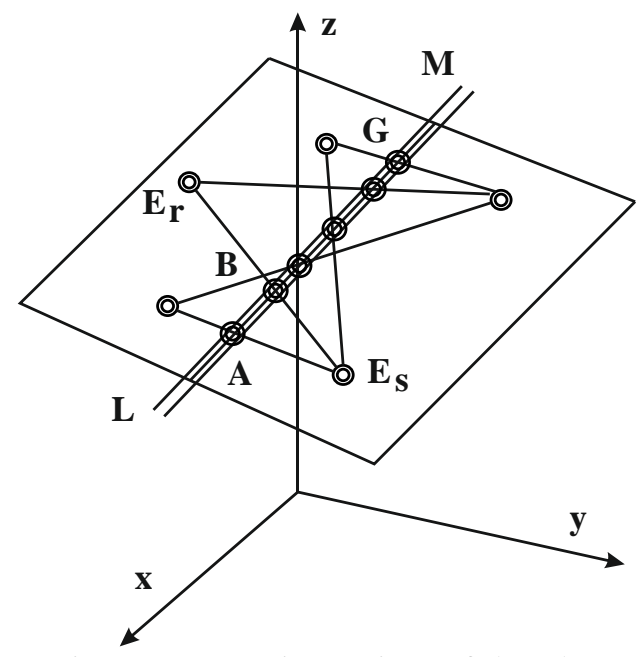

Fig. 1: Supporting points of the plan

We assume that obtained linear model of the function of the plan (11) is the matrix of the plan $m^{*} n$ in the coded values of $x_{i j}, i=1,2,3, \ldots, m$ is the number of experts, $j=1,2,3, \ldots, n$ is the number of factors

(Table 1).

Table 1: Matrix of the action plan

\begin{tabular}{|c|c|c|c|c|}
\hline$i / j$ & $x_{1}$ & $x_{2}$ & $\cdots$ & $x_{n}$ \\
\hline 1 & $x_{11}$ & $x_{12}$ & $\cdots$ & $x_{1 n}$ \\
\hline 2 & $x_{21}$ & $x_{22}$ & $\cdots$ & $x_{2 n}$ \\
\hline$\ldots$ & $\ldots$ & $\ldots$ & $\ldots$ & $\ldots$ \\
\hline$m$ & $x_{m 1}$ & $x_{m 2}$ & $\cdots$ & $x_{m n}$ \\
\hline
\end{tabular}

It is necessary for the $\mathrm{i}$-th line of Table $1(i=1,2,3, \ldots, m)$ to find the sequence $\left\{z_{i}\right\}$ of the values of the plan 11 at points of expert estimates, the difference $1-z_{i}$ i and the module difference $\left|1-z_{i}\right|$ and complete Table 2.

Table 2: The matrix of the plan in coded values

\begin{tabular}{|c|c|c|}
\hline$i$ & $1-z_{i}$ & $\left|1-z_{i}\right|$ \\
\hline 1 & $1-z_{1}$ & $\left|1-z_{1}\right|$ \\
\hline$\ldots$ & $\ldots$ & $\ldots$ \\
\hline$m$ & $1-z_{m}$ & $\left|1-z_{m}\right|$ \\
\hline
\end{tabular}

Obtained differences of $1-z_{i}$ have different signs and correspond to the points of (11) plan on different sides of admissible (or operational) plans hyperline (Fig. 1), with segments $E_{r}, E_{s}$, connecting points of expert estimates, for which $1-z_{r}>0$, and $1-z_{s}<0$, define operational plans. The number of operational plans is equal to the product of number of lines in Table 2 , where $1-z_{i}>0$, and the number of lines, where $1-z_{i}<0$. This number is the number of admissible pairs, on which we find points below by successive approximations:

$A\left(x_{1}, x_{2}, x_{3}, \ldots, x_{n}\right)_{A}, B\left(x_{1}, x_{2}, x_{3}, \ldots, x_{n}\right)_{B}, \ldots, G\left(x_{1}, x_{2}, x_{3}, \ldots, x_{n}\right)_{G}$.

According to Tables 2 and 3 we form all possible pairs $\mathrm{r}, \mathrm{s}$, where $1-z_{r}>0,1-z_{s}<0$. For each such pair, 
we complete Table 3.

Table 3: The value of the plan's function at points of expert estimates

\begin{tabular}{|c|c|c|c|c|c|}
\hline$I$ & $x_{1}$ & $\cdots$ & $x_{n}$ & $1-z_{i}$ & $\left|1-z_{i}\right|$ \\
\hline$r$ & $x_{r 1}$ & $\cdots$ & $x_{r m}$ & $1-z_{r}$ & $\left|1-z_{r}\right|$ \\
\hline$s$ & $x_{s 1}$ & $\cdots$ & $x_{s n}$ & $1-z_{s}$ & $\left|1-z_{s}\right|$ \\
\hline
\end{tabular}

The exact operational plan stipulated by expert pair $(\mathrm{r}, \mathrm{s}$,$) , we find according to the known formulas of$ segment division in the given ratio $\lambda$ :

$$
\left\{\begin{array}{l}
x_{1}=\frac{x_{s 1}+\lambda_{r s} x_{r 1}}{1+\lambda_{r s}} \\
x_{2}=\frac{x_{s 2}+\lambda_{r s} x_{r 2}}{1+\lambda_{r s}} \\
x_{3}=\frac{x_{s 3}+\lambda_{r s} x_{r 3}}{1+\lambda_{r s}}, \\
\ldots \ldots \ldots \ldots \ldots \ldots \ldots \ldots \ldots \ldots \ldots \ldots \ldots \\
x_{n}=\frac{x_{s n}+\lambda_{r s} x_{r n}}{1+\lambda_{r s}}
\end{array}\right.
$$

In formulas (16) he number $\lambda_{r s}$ is the ratio of the modulus of the differences $\left|1-z_{s}\right|,\left|1-z_{r}\right|$, as such

$$
\lambda_{r s}=\frac{\left|1-z_{s}\right|}{\left|1-z_{r}\right|},
$$

while number in the fraction 17 numerator must be smaller of the compared. In addition, the elements of Table 4 row are multiplied by $\lambda_{r s}$ for which

$$
\left|1-z_{r}\right|>\left|1-z_{s}\right|
$$

Formulated rules (17), (18 are derived from the geometric content of segment division in the given ratio. If the operational plan calculations are correct, then the coordinates (16) satisfy the identity (14) with the error $\varepsilon$, which does not exceed the miscalculations.

On the set of received operational plans according to the chosen optimization criterion we determine the reference (optimal) plan, which corresponds to the initial expert estimates. In the case of selecting two or more criteria, we obtain a multi-criteria model of the optimal plan. The problem of unambiguous choice of a multicriterial model does not always has a solution, especially with a large number of factor features of the plan (variables $x_{i j}$ ).

As an optimization criterion we take the sum of coordinates (16) of the operational plan that equally satisfies the equation (11), that is

$$
K_{i}=\sum_{i=1}^{n} x_{i}=x_{1}+x_{2}+x_{3}+\ldots+x_{n(A \neq B \neq . . \neq G)},
$$

where $x_{i}$ is the coded value, and the reference (optimal) plan is that of the operational plans that satisfies condition

$$
\min \left(\Sigma_{A}, \Sigma_{B}, \ldots, \Sigma_{G}\right)
$$

The number $K_{i}$ we will call a multidimensional optimality criterion. Note, that the number of operational 
plans, and, accordingly, the number of sums $\sum_{i}$, is equal to the product of expert points number located on both sides of the hyperline. So, if 4 expert points satisfy one of the inequalities in 15 , and 3 expert points satisfy the other (for $\mathrm{m}=7$ ), then there will be 12 operational plans. Generally, only one among them is optimal by criterion (20). If it turns out that two or more plans correspond to the optimality condition, then an additional condition should be placed for plans that are equivalent on the optimality condition. That will allow for an unambiguous choice.

The reference plan is intended to serve as a generally accepted norm, or a standard that regulates and optimizes the development and improvement of intangible assets of an enterprise. The reference plan is developed for a specific category of enterprises at a given level of the hierarchy.

A reference plan recommended for a number of objective reasons, for example under conditions of underfunding, may not always be fully implemented. Certain deviations from the standard, respectively, put the problem of comparing the practically executed plan with its theoretical standard. The task of comparing objects (in this case, reference and operational plans) is usually solved, basing on the concept of these objects efficiency.

\section{The method for assessing the effectiveness of alternative plans}

On the next stage of the research we propose the method for assessing the effectiveness of alternative plans. Implementation of some proposed plan for the development and improvement of intangible assets of the enterprise on the set of $\left\{x_{1}, x_{2}, x_{3}, \ldots, x_{n}\right\}$ random numerical values of factor characteristics $\left\{X_{1}, X_{2}, X_{3}, \ldots, X_{n}\right\}$ is an event that provides with certain probability extent of such development and improvement that is sufficient for the successful solution of the tasks.

A priori probability of the level of improvement and development of intangible assets provided by the developed plan, we call the effectiveness of the plan. A stochastic function, which expresses this opportunity, is called the function of the plan's effectiveness. We will consider the criterion of optimality of the plan as an argument of efficiency function.

For the analytical construction of the efficiency function we use the results of operational plans calculations. In this case, we assume that the efficiency of the reference plan has a maximum value and is equal to 1 (according to the definition of probability).

Let take $K_{i}$ a s a criterion of the operational plan optimality with the number i, $K_{e}$ is the criterion of the reference plan optimality. The difference

$$
\Delta K=K_{i}-K_{e}
$$

is an increase in the plan i optimality criterion. In this case, the quantity

$$
\Delta p=\frac{K_{i}-K_{e}}{K_{e}},
$$

can characterize a change in efficiency when using a certain version of the operational plan instead of the reference. Consequently, for the effectiveness of the operational plan, we obtain the formula

$$
P_{i}=1-\frac{\Delta K}{K_{e}}
$$

The efficiency function (23) turns into the form:

$$
P=1-\frac{K-K_{e}}{K_{e}}
$$

and can be used to assess the effectiveness of any alternative plan, not necessarily operational. In this case, the above condition of admissibility should be replaced by a more rigid:

$$
K_{e} \leq K \leq 2 K_{e},
$$


where $K$-is a criterion of the alternative plan optimality, $K_{e}-$ is the reference plan optimality criterion. An index $K$ is calculated in coded coordinates, basing on values of variables $x_{i}$, put into an alternative plan.

Let's find out the geometric meaning of the plan's efficiency function, (Fig. 2), conditioned by expression (24), noting that, with monotonous growth $K$ within the limits of (25) the ratio $\left(K-K_{e}\right) / K_{e}$ monotonically increases from 0 to 1 .

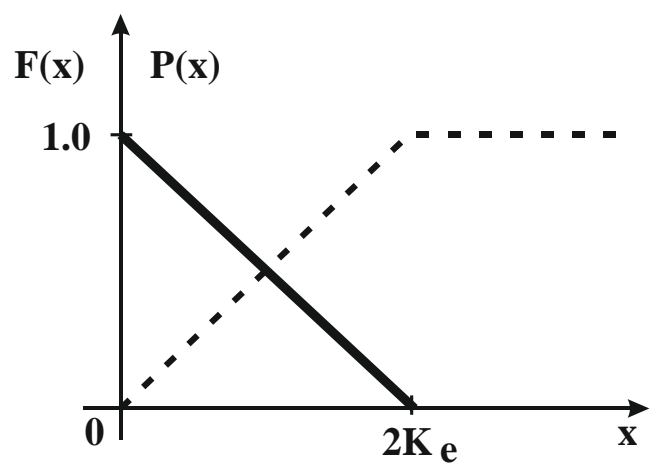

Fig.2: Graphs of efficiency and distribution functions

Let's state the current value $\mathrm{x}$ of the random size $\mathrm{X}$ for the current value of a random size $\mathrm{K}$.

$$
X=\frac{K-K_{e}}{K_{e}},
$$

Then the distribution function of this random variable will be written in the following way

$$
F(x)=\left\{\begin{array}{ll}
x, \text { if } & 0 \leq x<1, K_{e} \leq K<2 K_{e} \\
1, \text { if } & x \geq 1, K \geq 2 K_{e}
\end{array},\right.
$$

In this case, the efficiency function (24) is nothing else than an addition of the distribution function $F(x)$ to 1 . Fig. 2 shows graphs of both functions.

\section{Obtained results}

The proposed approach to measures planning optimization of the enterprise's intangible assets further development was used at the PJSC Temp Plant, Khmelnytskyi (the research was conducted within the framework of the scientific and research state project of the Khmelnytskyi National University, No. 8-2016). While choosing qualitative indicators and criteria for the intangible assets development, the following factors were taken into account: a wide range of results and ideas from the intangible assets formation; ways of preserving the market position of the enterprise; new tools for earning extra income. The complexity of information arrays processing was solved by automating the optimal plans formation processes and determining their effectiveness with the use of Visual Studio 2017 and MS SQL Server 2017. The following modules were developed (Table 4).

Table 4. Software complex of intangible assets formation processes automation

\begin{tabular}{|l|l|}
\hline Module name & \multicolumn{1}{|c|}{ Function } \\
\hline AWP.exe & Main controlling program \\
\hline Lin_func.dll & The plan effectiveness calculation library \\
\hline Matemat.dll & The plan effectiveness calculation library basing on rank ratings \\
\hline Unit 1.cs & Provides a dialogue scheme of the plan effectiveness calculating system \\
\hline Unit 2.cs & Provides authorized access to the plan effectiveness calculating system \\
\hline Unit 3.cs & $\begin{array}{l}\text { Calculating determinant; carrying out the plan effectiveness basic calculations; definition of } \\
\text { the plan's function }\end{array}$ \\
\hline
\end{tabular}


PEN Vol. 7, No. 2, August 2019, pp.618-628

\begin{tabular}{|l|l|}
\hline Unit 4.cs & Determination of the plan's recommended options \\
\hline Unit 5.cs & Reference points derivation \\
\hline Unit 6.cs & Operational plans definition \\
\hline Unit 7.cs & Alternative plan effectiveness calculation \\
\hline Unit 8.cs & Provides a dialogue scheme of the plan effectiveness calculation basing on rank ratings \\
\hline Unit 9.cs & $\begin{array}{l}\text { Provides authorized access to the work of the plan effectiveness calculation system basing } \\
\text { on rank ratings. }\end{array}$ \\
\hline Unit 10.cs & $\begin{array}{l}\text { Conducts basic calculations of the plan's effectiveness; determines the plan's function using } \\
\text { rank ratings }\end{array}$ \\
\hline Unit 11.cs & Determining the sample values of the plan's activities \\
\hline
\end{tabular}

According to the calculations' results a system of measures was developed for the enterprise PJSC Temp Plant. These measures could ensure the economic growth of the enterprise in the long run on the basis of the company's intangible assets development in the following areas: development of computer systems and technologies; intellectualization of labor; expansion of economic interactions network in the context of interaction with market mechanisms; formation of innovations and innovative ideas for improving the quality of products and their competitiveness in the market.

\section{Conclusions}

Our research is devoted to the construction of scientific and methodological approaches to improving the enterprise's intangible assets planning and development processes. The solution of this problem is connected with the fact that intangible assets at the present stage of scientific and technological development acquire a dominant position in comparison with tangible assets to ensure the enterprises' successful operation. The lack of material form, close relationship with investment processes, diverse results of the influence on the company's activities (ensuring profit increase, market value growth, creating informational environment, raising social and economic standards, etc.) give preference to assessing their availability, improvement and development according to qualitative indicators that are not reflected in the financial statements.

The obtained results allow formulating an integrated approach in planning the enterprise intangible assets development, based on modern scientific and mathematical methods and conclusions of scientists and experts, which allow using both quantitative and qualitative indicators. The proposed methods allow to solve the following tasks: finding the linear function of the enterprise's intangible assets improvement and development plan, assessing the adequacy of the plan's linear function to the input data, determining the optimal plan for a given set of factor characteristics, determining the reference values of the plan indicators, and determining the effectiveness of the proposed action plan.

The developed method of effectiveness assessing the improvement and development plan of enterprise intangible assets provides an opportunity to take into account all changes taking place in the informationeconomic, intellectual, financial and organizational spheres. Its application is possible at enterprises with different forms of ownership in various branches of the national economy. The value of the proposed approach is that, it can be used to carry out the relevant calculations of operational and strategic planning of the intangible assets development in such important areas as energy, machinery, etc. without making any changes.

The obtained practical results show the increase of administrative decisions efficiency on the basis of planning optimization measures for enterprises' intangible assets development and improvement.

\section{References}

[1] V. Babenko, O. Nazarenko, I. Nazarenko, O. Mandych, M. Krutko,. Aspects of program control over technological innovations with consideration of risks. Eastern-European Journal of Enterprise Technologies. Vol. 3/4 (93), pp. 6-14, 2018.

[2] M. G. Kolomiets, O.V. Melentsova, D.K. Kondratenko, V.M. Osnadchuk. Intangible assets as an actual factor for increasing the market price of the company.Economic Theory and Law. No. 3, pp. 43-55, 2016 
[3] V. Vovk, S. Pryima, I. Shysh, et al. Modeling of organizational processes in entrepreneurship: monograph, 2011.

[4] M.P. Voynarenko, L.V. Dzhulliy, L.V. Yemchuk. Information technology in the organizational management of the enterprise. Konzeptuelle Grundsatze des Wirtschaftswachstums bei der Globalisierung : kollektive monographie, herausgegeben vom Doktor Wirtschaftswissenschaften, Professor W. Jatsenko, 2016.

[5] Mehta, Archana Dinesh and Madhani, M. Pankaj. Intangible Assets - An Introduction. The Accounting World. Vol. 8, No. 9, pp. 11-19 2008.

[6] V.M. Heits, et al. Innovative Ukraine 2020. National report. Publisher: National academy of science of Ukraine, 2015.

[7] B. Lev. Intangibles: management, measurement, and reporting, Brookings Institution Press, Washington, D.C. 2003.

[8] Z. M. Sokolovska, V. M. Andrienko, I. Yu Ivchenko. Mathematical and computer modeling of economic processes. Monograph, 2016.

[9] I. M. Kutsyk, Z. P. Drohobyczky, H. I. Plisa. Accounting concept of the of intangible assets value management on the enterprise: monograph. Lviv: Raster-7, 2016.

[10] I. Odotyuk. Domestic industry of high technologies: knowledge, innovation, investment factors of its formation and development. Bulletin of the National Academy of Sciences of Ukraine, No11, pp. 21-33, 2011.

[11] I. Y. Yaremko, et al. Economic categories in accounting methodology: monograph. Lviv: Kamenyar, 2002.

[12] M.P. Voynarenko, L.V. Yemchuk. Information Mechanisms for Management of Economic Processes: report on research workers, 2018.

[13] Ya.P. Kvach. Estimation of intangible assets in the context of diagnosing economic safety of the enterprise. Foreign Trade: Economics, Finance, Law. No. 5-6, pp. 218-225.

[14] V.S. Shelest. Methodical provisions of the analysis of the use of intangible assets of innovation-oriented enterprises. Scientific Papers of Kirovograd National Technical University. Economic Sciences. Issue 27, pp. 55-268, 2015.

[15] A. Niculita, A. Popa, F. Caloian. The Intangible Assets-A New Dimension in The Company's Success. Procedia Economics and Finance. Volume 3, pp. 304-308, 2012.

[16] Yu.Ya. Samokhvalov, E.M. Naumenko, et al. Expert assessment: methodical aspect: monograph. Kiev: DUIKT 2007.

[17] S. Ulubeyli, A. Kazaz, V. Arslan. A Structured Selection Process for Small and Medium Enterprises in Construction Industry: Case of International Projects Periodicals of Engineering and Natural Sciences. Vol 5, No 3, pp. 263-270, 2017.

[18] I. A. Chub, M.V. Novozhilova, V.A. Andronov, et al. Modeling of applied optimization problems of objects with changing metric characteristics: monograph. Kharkiv: NUTZZ of Ukraine, 2017.

[19] I.V. Bril, et al. Formation and use of intangible assets of enterprises to increase their capitalization: monograph. National Academy of Sciences of Ukraine, Institute of Industrial Economics. Kyiv, 2015.

[20] A.O. Epiphanova, et al. Modern and perspective methods and models of management in economics: monograph. Sumy: DAB "Oasis NBU", Part 2, 2008.

[21] P. P. Sengupta, M. Sinha, Uj. P. Dutta. Economic and environmental performances in manufacturing industries: A comparative study. Periodicals of Engineering and Natural Sciences. Vol 7, No 1, pp. 99$108,2019$. 